\title{
Assessment of Risk and Emergency Knowledge Level - Cardiovascular Emergencies in Rural Communities Sungai Nagara, Margasari Village, Tapin, South Kalimantan
}

\author{
Abdurahman Wahid*, Hasby Prichoiruna, Ainun, Muhamad Muzakir \\ School Of Nursing, Faculty of Medicine, Universitas Lambung Mangkurat, Indonesia \\ Corresponding author: ns.wahid@ulm.ac.id
}

\begin{abstract}
Background: Cardiovascular disease contributes to a massive mortality rate in the world and also in Indonesia. Assessment of the risk and level of knowledge of cardiac emergency symptoms needs to be carried out, especially in rural areas where access to cardiovascular treatment is far.

Purpose: This study aimed to assess risk stratification and the level of knowledge.

Methods: The method of measuring risk and level of knowledge was carried out on 100 Margasari Ilir respondent who were over 40 years old and carried out using the stratified random sampling method during September 2020 - measuring risk using the instrument Framingham Risk Score and the level of knowledge using the ACS Response Index.

Results: The average age of respondents was 54.98 years, 30 men (30\%) and 70 women (70\%), 22 smokers (22\%), seven diabetes mellitus (7\%), 11 people (11\%) had high cholesterol, 41 people (41\%) had hypertension, and 33 people $(33 \%)$ had low HDL levels. The number of people who have a high risk of emergency - cardiovascular emergency is seven people (7\%), 24 people are at moderate risk (24\%), and 69 people are at low risk $(69 \%)$. The level of knowledge about cardiac emergencies is in the low category of 80 people (80\%), 19 people (19\%), and one high (1\%).

Conclusion: It is necessary to increase public knowledge about cardiovascular emergencies.
\end{abstract}

Keywords: Risk Stratification, Cardiovascular Diseases, Framingham, ACS. 
Journal Of Nursing Practice

http://thejnp.org

ISSN: 2614-3488 (print); 2614-3496 (online)

Vol.4 No.2. April 2021. Page.196-203

\section{BACKGROUND}

Cardiovascular disease has an immense contribution to death in the world. The World

Health Organization (WHO) in 2012 reported that the estimated death rate from cardiovascular disease was 17.5 million deaths, with $37 \%$ of them occurring under 70 years of age (World Health Organization, n.d.-a). In Southeast Asia, cardiovascular disease is one of the leading causes of death caused by non-communicable diseases. Noted that this disease contributes to $25 \%$ of deaths in the category of non-communicable diseases (Otgontuya et al., 2011). In Indonesia, based on the results of Basic Health Research (Riskesdas 2018), the prevalence of the cardiovascular disease is $1.5 \%$ or at least $2,784,064$ people in Indonesia have the cardiovascular disease (Kementrian Kesehatan Republik Indonesia, 2018).

Cardiovascular disease can lead to emergency conditions as an acute coronary syndrome (ACS). The acute coronary syndrome is a condition of blockage of the coronary heart, causing chest pain due to heart cell ischemia. Ischemia will cause damage to the structure of the heart, which can lead to decreased pumping ability of the heart and rhythm disturbances. The longer it is left alone, the more heart cells are damaged, and the patient is at risk of death ( $\mathrm{O}^{\prime}$ Connor et al., 2015). This condition requires fast and precise treatment so that death can be prevented. Practical assistance must be carried out in a chain from the community level, during transportation, while in the Emergency Unit (ER), and intensive care (Kronick et al., 2015).

Margasari Ilir is a village on the banks of the Nagara River, located in Candi Laras Utara, Tapin Regency, South Kalimantan. The distance from the village to the hospital with the nearest Emergency Unit (UGD) facility is $30 \mathrm{~km}$ and can be reached within 40 minutes. The distance from a hospital that has cardiologists is $50 \mathrm{~km}$. The health facilities available around the village within a $5 \mathrm{~km}$ radius are 2 Primary Health Care and two midwifery clinics. This facility is certainly not sufficient to deal with ACS conditions if it occurs in the village community. Primary Health Care and midwifery clinics are health facilities for essential services, not emergency (Harrison et al., 2015).

Based on this situation, the incidence of Acute Coronary Syndrome will be a big problem if it occurs in that area. This condition must be treated quickly to prevent death and disability (O’Connor et al., 2015).

To anticipate the above conditions, it is necessary for performing a risk assessment of ACS events in this area. One method that can be used is the Framingham Risk Score. This method has been developed since 1971 and continues to get updates until now. The components in this stratification are age, gender, total cholesterol, High-Density Lipoprotein (HDL), blood pressure, diabetes status, and smoking status (Wilson et al., 1998).

The World Health Assembly (WHA) made a consensus that by 2025 there should be a 25\% reduction in mortality at the age of 30-70 compared to deaths in 2010 in low and middle-income countries (Bovet et al., 2015). Risk mapping is one crucial step towards achieving this. According to the World Health Organization (WHO) recommendations, risk reduction is performed through lifestyle modifications according to the risk category in the community. In the low-risk group, modification focuses on lifestyle changes. For a moderate-risk community, risk factor monitoring is also required every 6 - 12 months. As for high-risk communities, lifestyle changes are accompanied by risk factor monitoring every 3-6 months (World Health Organization, n.d.-b).

Another critical aspect that must be strengthened is people's knowledge in recognizing the signs and symptoms of ACS. Good knowledge, coupled with the right attitude, will encourage people to act quickly and appropriately. The longer they do not get help, the greater the damage to the heart and can cause death (O'Connor et al., 2015). 


\section{Journal Of Nursing Practice}

http://thejnp.org

ISSN: 2614-3488 (print); 2614-3496 (online)

Vol.4 No.2. April 2021. Page.196-203

\section{OBJECTIVE}

This study aims to assess risk stratification and the level of knowledge of the Margasari Ilir village community on ACS.

\section{METHODS}

This research is a descriptive-analytical study. The variables measured were the level of risk and the level of public knowledge about ACS. Data were collected on age, sex, smoking status, total cholesterol, HDL count, systolic pressure, and hypertension treatment status. The instrument for measuring the level of risk uses the application Framingham Coronary Heart Diseases from the page www.mdcalc.com. The risk classification includes low risk (score $<10 \%$ ), medium risk (score 10-20\%), and high risk (score $>20 \%$ ) [7]. Measuring the level of knowledge using the instrument Acute Coronary Syndromes (ACS) Response Index.

Data collection was carried out during September 2020 involving 100 respondents who were determined through Cluster Random Sampling technique. The tools used in data collection were interview sheets, digital tensimeter brand Omron HEM 8172, Lipid Pro meter, pro lipid sticks, and ACS Response Index questionnaire.

In the context to transmission prevention of Covid - 19, this research was conducted by a research assistant who is a student of the Nursing Study Program at University Lambung Mangkurat and lives in the research area. Data collection will be carried out by visiting the respondents one by one to their house, in order to avoid forming a crowding.

Data was collected with permission from the Government of Tapin Regency. All Respondents have been given an explanation about benefits, risks, and confidentiality before taking consent.

\section{RESULTS}

Demographic Characteristics

Table 1. Age Characteristic

\begin{tabular}{llllll}
\hline Variable & Mean & Min & Max & St Dev & $95 \%$ CI \\
\hline Age (year) & 54.9 & 40 & 79 & 10.0 & 1.997 \\
\hline
\end{tabular}

Based on WHO criteria, this 54.98-year-old is included in the adult category.

Table 2. Risk factor

\begin{tabular}{llcc}
\hline \multirow{2}{*}{ Variable } & & Tota & Persentage \\
& & 1 & \\
\hline \multirow{2}{*}{ Gender } & Male & 30 & $30 \%$ \\
\cline { 2 - 4 } & Female & 70 & $70 \%$ \\
\hline \multirow{2}{*}{ Diabetes } & Yes & 22 & $22 \%$ \\
\cline { 2 - 4 } & No & 78 & $78 \%$ \\
\hline \multirow{2}{*}{ Total Cholesterol } & Yes & 7 & $7 \%$ \\
\cline { 2 - 4 } & No & 93 & $93 \%$ \\
\hline Blood Pressure & High & 11 & $11 \%$ \\
\cline { 2 - 4 } & Normal & 89 & $89 \%$ \\
\hline Hypertension Treatment & High & 41 & $41 \%$ \\
\cline { 2 - 4 } & Normal & 59 & $59 \%$ \\
\cline { 2 - 4 } & Controlled & 28 & $28 \%$ \\
\cline { 2 - 4 } & NO & 72 & $72 \%$ \\
\hline
\end{tabular}




\section{Journal Of Nursing Practice}

\begin{tabular}{llll}
\cline { 3 - 4 } HDL & Low & 44 & $44 \%$ \\
\cline { 2 - 4 } & Moderate & 35 & $35 \%$ \\
\cline { 2 - 4 } & High & 21 & $21 \%$ \\
\hline Total & & 100 & $100 \%$ \\
\hline
\end{tabular}

In this study, there were more women than men, namely $70(70 \%)$ women and $30(30 \%)$ men. The number of smokers was 22 people $(22 \%)$, all of whom were men. Respondents with diabetes were seven people $(7 \%)$ with the proportion of women six people $(6 \%)$ and men - 1 person (1\%). Also, there were 11 respondents with high total cholesterol. The number of respondents with hypertension was 41 people (41\%) and 28 people who received routine treatment $(28 \%)$.

Table 3. Description of total cholesterol, HDL, and systolic pressure

\begin{tabular}{llllll}
\hline Variable & Mean & Min & Max & St Dev & $95 \%$ CI \\
\hline Age & 54.98 & 40 & 79 & 10.01 & 1.997 \\
\hline Total cholesterol $(\mathrm{mg} / \mathrm{dl})$ & 160 & 100 & 252 & 36.49 & 7.27 \\
\hline HDL $(\mathrm{mg} / \mathrm{dl})$ & 43 & 25 & 70 & 13.72 & 2.73 \\
\hline Systolic pressure $(\mathrm{mmHg})$ & 138.31 & 73 & 206 & 27.42 & 5.46 \\
\hline
\end{tabular}

\section{Ten-year emergency risk using Framingham}

Risk factors are calculated using the Framingham Risk Stratification. The risk classification is divided into 3 levels, low risk $(<10 \%)$, medium risk (10-20\%) and high risk $(>20 \%)$ [10]. Based on the calculation of risk factors for a cardiac emergency, it was found that seven people $(7 \%)$ of the Margasari villagers had high risk, 24 people $(24 \%)$ had moderate risk factors, and 69 people $(69 \%)$ had low-risk factors.

\begin{tabular}{lcccc}
\hline Gender & Age & \multicolumn{3}{c}{ Risk Level } \\
\cline { 2 - 5 } & & Low & Moderate & High \\
\hline Male & $40-49$ & 10 & 2 & 0 \\
\cline { 2 - 5 } & $50-59$ & 3 & 4 & 0 \\
\cline { 2 - 5 } & $60-69$ & 0 & 6 & 3 \\
\hline \multirow{3}{*}{ Female } & $70-79$ & 0 & 1 & 1 \\
\cline { 2 - 5 } & $40-49$ & 24 & 0 & 0 \\
\cline { 2 - 5 } & $50-59$ & 23 & 0 & 0 \\
\hline Total & $60-69$ & 6 & 3 & 0 \\
\hline \multirow{2}{*}{ Bo- 79} & 3 & 8 & 3 \\
\hline
\end{tabular}

Based on age, all those who have a high risk are in the age group over 60 years. The distribution is more evenly found in the moderate risk group, namely in all groups aged 40 years and over in men (13 people), but only in women in the age group 60 years and over. The highest number of low-risk groups was found in women in the 40 to 59 years age group, namely 47 people $(47 \%)$ and at the age of 60 years and over, nine women with low-risk factors were found. In men aged 40 to 59 years, found 13 people (13\%) who had a low risk and at the age above 60 years in men was no longer found to be low risk

\section{Knowledge Level}

Measurement of the level of knowledge is carried out using the instrument ACS Response Index. The level of knowledge is categorized as high if the correct answer is $>70 \%(15$ 
items), moderate if the answer is correct $40-70 \%$ (8-14 items), and the low category if $<40 \%$ (less than eight items) (O'Brien et al., 2013).

Table 5. Knowledge description

\begin{tabular}{llllll}
\hline Variable & Mean & Min & Max & St Dev & $95 \%$ CI \\
\hline Knowledge & 6,83 & 6 & 16 & 1.86 & 0.36 \\
\hline
\end{tabular}

Based on the results of knowledge, it is found that most respondents have a low level of knowledge, namely 80 people ( $80 \%$ ), and only one person has a high level of knowledge.

Table 6. Knowledge level

\begin{tabular}{rlcc}
\hline \multicolumn{1}{c}{ Variable } & & Total & Persentage \\
\hline Knowledge level & Low & 80 & $80 \%$ \\
\cline { 2 - 4 } & Moderate & 19 & $19 \%$ \\
\cline { 2 - 4 } & High & 1 & $1 \%$ \\
\hline
\end{tabular}

\section{DISCUSSION}

The proportion of the population at high risk in Margasari Village is 7\%, which is higher than the national result in other countries in the Southeast Asia, Cambodia (1.6\%) and Malaysia (2.3\%), with an equivalent age group average [12]. However, this figure is lower than in some countries in the age group for over 40 years. In comparison, the proportion of the population at high risk in rural India is $17.8 \%$, Nigeria is $14.6 \%$, and Romania is 11\% (Babatunde et al., 2020; Praveen et al., 2018; Rosu et al., 2018).

The most common risk factor for the population is hypertension, with 41 people (41\%) followed by smoking in $22(22 \%)$, both of which are factors that can be changed with behaviour modification. In people with hypertension, controlled treatment was carried out by 28 people (68\%). Globally, hypertension is the largest contributor to the increase in risk factors for cardiac emergencies in low, medium and high-income countries. Based on a study by Chow et al. (2013), from 142,041 people from 10 countries (3 from high-income countries, ten from middle-income countries, and four from low-income countries), the number of hypertension sufferers was 57,840 people $(40.8 \%)$. The number who did controlled treatment was only 7634 people $(32.5 \%)$ (Chow et al., 2013).

Efforts to modify risk factors can be done with two strategies; modification in the population and modification in the people with high risk. The implementation of populationbased strategy can be done at the village level by building a smoke-free village. Another effort that can be made at the national level is to increase the tobacco tax so that the price of cigarettes will also increase, thereby reducing public access to cigarettes (Bovet et al., 2015).

Other efforts focus on interventions of high-risk populations. Some of the interventions that can be done include prevention and treatment of hypertension, cholesterol management, treatment of dyslipidemia, and also control of diabetes mellitus. Early detection of risk factors will help reduce mortality from cardiovascular disease. An example of early detection management can be seen in the guidelines issued by the US Preventive Service Task Force (USPSTF). Blood pressure screening is carried out on citizens since the age of 18 years, screening for dyslipidemia is carried out from the age of 35 years in men and 45 years in women, and diabetes mellitus screening some individuals are at risk of diabetes (Bovet et al., 2015). In developing countries such as Indonesia, these efforts can also be adopted by optimizing the role of Community Health Centers and Integrated Service Post Cadres (Posyandu). Screening can be done by adopting the WHO / ISH (World Health Organization / International Society of Hypertension) Prediction Chart method, which was introduced in 2007. This method can be used in areas where cholesterol checks cannot be done due to the difficulty of access or high prices (World Health Organization, n.d.-c). 


\section{Journal Of Nursing Practice}

http://thejnp.org

Another strategy is increasing public knowledge about cardiovascular diseases, especially emergency conditions such as acute coronary syndrome, stroke, and cardiac arrest. In this study, it can be seen that the public's knowledge about cardiac emergency symptoms is still deficient.

Knowledge is one of the factors that increase the success and adherence to treatment in people who have risk factors. Several studies have shown a strong relationship between the level of knowledge and the level of adherence in carrying out therapy in hypertensive patients. In a study conducted by McDermot et al. (2003) in a group of patients with peripheral artery disease, coronary artery disease, and no health problems, it was found that the group with a lower assessment of the risk of cardiovascular emergencies had a lower control rate for treatment (McDermott et al., 2003).

Increasing knowledge can be done by providing information to the public by health education and also providing reading material in the community about the dangers of cardiovascular disease. Materials that can be given include the introduction of risk factors, recognition of signs and symptoms in case of emergency, efforts that can be made as first aid in case of emergency conditions, and how to seek medical help. Efforts to increase literacy are in line with increasing public knowledge, and also in line with adherence to control and medication if there is a risk (Chajaee et al., 2018) (Ghaffari-Fam et al., 2020).

\section{CONCLUSION}

There are $7 \%$ of respondents in Margasari Ilir village who have a high risk, $24 \%$ have a moderate risk, and $69 \%$ have a low risk in the next ten years to experience cardiovascular emergencies. The risk factors with the highest proportion were hypertension (41\%) and smoking (22\%).

The level of knowledge possessed by the community about signs and symptoms of emergency heart conditions is in the low category of $80 \%, 19 \%$ medium, and $1 \%$ high. More intensive education is needed so that people can recognize cardiovascular events. 


\section{Journal Of Nursing Practice}

http://thejnp.org

ISSN: 2614-3488 (print); 2614-3496 (online)

Vol.4 No.2. April 2021. Page.196-203

\section{REFERENCES}

Babatunde, O. A., Olarewaju, S. 0., Adeomi, A. A., Akande, J. O., Bashorun, A., Umeokonkwo, C. D., \& Bamidele, J. O. (2020). 10-year risk for cardiovascular diseases using WHO prediction chart: Findings from the civil servants in Southwestern Nigeria. BMC Cardiovascular Disorders, 20(1). https://doi.org/10.1186/s12872-020-01438-9

Bovet, P., Chiolero, A., Paccaud, F., \& Banatvala, N. (2015). Screening for cardiovascular disease risk and subsequent management in low and middle income countries: Challenges and opportunities. In Public Health Reviews (Vol. 36, Issue 1). EHESP Presses. https://doi.org/10.1186/s40985-015-0013-0

Chajaee, F., Pirzadeh, A., Hasanzadeh, A., \& Mostafavi, F. (2018). http://www.ephysician.ir/index.php/browse-issues/10/3/979-6470. Electronic Physician, 10(3), 6470-6477. https://doi.org/10.19082/6470

Chow, C. K., Teo, K. K., Rangarajan, S., Islam, S., Gupta, R., Avezum, A., Bahonar, A., Chifamba, J., Dagenais, G., Diaz, R., Kazmi, K., Lanas, F., Wei, L., Lopez-Jaramillo, P., Fanghong, L., Ismail, N. H., Puoane, T., Rosengren, A., Szuba, A., ... Yusuf, S. (2013). Prevalence, awareness, treatment, and control of hypertension in rural and urban communities in high-, middle-, and low-income countries. JAMA Journal of the American Medical Association, 310(9), 959-968. https://doi.org/10.1001/jama.2013.184182

Ghaffari-Fam, S., Sarbazi, E., Ardabili, F., Babazadeh, T., Darghahi, G., \& Jafaralilou, H. (2020). The role of health literacy in hypertension control: A cross-sectional study in Iran. Annali Di Igiene, 32(3), 263-273. https://doi.org/10.7416/ai.2020.2349

Harrison, R., Cohen, A. W. S., \& Walton, M. (2015). Patient safety and quality of care in developing countries in Southeast Asia: A systematic literature review. International Journal for Quality in Health Care, 27(4), 240-254. https://doi.org/10.1093/intqhc/mzv041

Kementrian Kesehatan Repuiblik Indonesia. (2018). Laporan_Nasional_RKD2018_FINAL.pdf. In Badan Penelitian dan Pengembangan Kesehatan (p. 198). http://labdata.litbang.kemkes.go.id/images/download/laporan/RKD/2018/L aporan Nasional RKD2018 FINAL.pdf

Kronick, S. L., Kurz, M. C., Lin, S., Edelson, D. P., Berg, R. A., Billi, J. E., Cabanas, J. G., Cone, D. C., Diercks, D. B., Foster, J., Meeks, R. A., Travers, A. H., \& Welsford, M. (2015). Part 4: Systems of care and continuous quality improvement: 2015 American Heart Association guidelines update for cardiopulmonary resuscitation and emergency cardiovascular care. Circulation, 132(18), S397-S413. https://doi.org/10.1161/CIR.0000000000000258

McDermott, M. M. G., Mandapat, A. L., Moates, A., Albay, M., Chiou, E., Celic, L., \& Greenland, P. (2003). Knowledge and attitudes regarding cardiovascular disease risk and prevention in patients with coronary or peripheral arterial disease. Archives of Internal Medicine, 163(18), 2157-2162. https://doi.org/10.1001/archinte.163.18.2157 


\section{Journal Of Nursing Practice}

http://thejnp.org

ISSN: 2614-3488 (print); 2614-3496 (online)

Vol.4 No.2. April 2021. Page.196-203

O’Brien, F., O’Donnell, S., McKee, G., Mooney, M., \& Moser, D. (2013). Knowledge, attitudes, and beliefs about acute coronary syndrome in patients diagnosed with ACS: An Irish cross-sectional study. European Journal of Cardiovascular Nursing, 12(2), 201-208. https://doi.org/10.1177/1474515112446544

O'Connor, R. E., Al Ali, A. S., Brady, W. J., Ghaemmaghami, C. A., Menon, V., Welsford, M., \& Shuster, M. (2015). Part 9: Acute coronary syndromes: 2015 American Heart Association guidelines update for cardiopulmonary resuscitation and emergency cardiovascular care. Circulation, 132(18), S483-S500. https://doi.org/10.1161/CIR.0000000000000263

Otgontuya, D., Oum, S., Buckley, B. S., \& Bonita, R. (2011). Assessment of total cardiovascular risk using WHO/ISH risk prediction charts in three low and middle income countries in Asia. https://doi.org/10.1186/2046-1682-4-13

Praveen, D., Peiris, D., MacMahon, S., Mogulluru, K., Raghu, A., Rodgers, A., Chilappagari, S., Prabhakaran, D., Clifford, G. D., Maulik, P. K., Atkins, E., Joshi, R., Heritier, S., Jan, S., \& Patel, A. (2018). Cardiovascular disease risk and comparison of different strategies for blood pressure management in rural India 11 Medical and Health Sciences 1102 Cardiorespiratory Medicine and Haematology 11 Medical and Health Sciences 1117 Public Health and Health Ser. BMC Public Health, 18(1). https://doi.org/10.1186/s12889-018-6142-x

Rosu, M. M., Popa, S. G., Mota, E., Popa, A., Manolache, M., Guja, C., Bala, C., \& Mota, M. (2018). Cardiovascular risk assessment in the adult (AGED 40-79 years) Romanian population. Acta Endocrinologica, 14(2), 227-234. https://doi.org/10.4183/aeb.2018.227

Wilson, P. W. F., D’Agostino, R. B., Levy, D., Belanger, A. M., Silbershatz, H., \& Kannel, W. B. (1998). Prediction of coronary heart disease using risk factor categories. Circulation, 97(18), 1837-1847. https://doi.org/10.1161/01.CIR.97.18.1837

World Health Organization. (n.d.-a). GLOBAL STATUS REPORT on noncommunicable diseases 2014 " Attaining the nine global noncommunicable diseases targets; a shared responsibility". WHO

World Health Organization. (n.d.-b). Prevention of Cardiovascular Disease. Pocket Guidelines for Assessment and ... - World Health Organization - Google Books. Retrieved October 30, 2020,

World Health Organization. (n.d.-c). WHO/ISH Risk prediction charts for 14 WHO epidemiological sub-regions [internet]. 2007. [cited 2017 Nov 19]. 